\title{
Implementasi Customer Relationship Management pada Industri Pendidikan: Studi Kasus Pada Akademi Pariwisata
}

\author{
Erna Kusumawati \\ Universitas Muhammadiyah Prof. Dr. Hamka, Indonesia. Erna_kusumawati@uhamka.ac.id
}

\begin{abstract}
ABSTRAK
Persaingan pada industri pendidikan semakin terasa, sehingga diberlakukan pengelolaan terhadap customer relationship. Paradigma dan cara berpikir industri pendidikan tidak lagi didominasi pada bagaimana mendapatkan siswa didik baru, tetapi berkembang kepada bagaimana mempertahankan pelanggan lama. Menelaah fenomena masalah pada industri pendidikan maka dilakukan penelitian terkait hubungan customer relationship management dan customer lifetime value. Penelitian dilakukan pada industri pendidikan, dimana orang tua siswa menjadi konsumen yang dikaji dalam penelitian ini. Sehingga dilakukan survei kepada 100 orang tua murid Sekolah Pariwisata yaitu Akademi Pariwisata NHI di Kota Bandung, Indonesia. Kajian dilakukan melalui analisis regresi dan data didapat secara kuantitatif melalui kuesioner. Hasil penelitian ditemukan bahwa customer relationship management yang dilakukan oleh sekolah memiliki dampak berarti pada peningkatan customer lifetime value. Orang tua akan memberikan rekomendasi terhadap investasi pendidikan kepada keluarga dan kolega bila merasakan kepuasan atas layanan yang diberikan oleh sekolah. Penelitian ini tentunya bermanfaat untuk industri pendidikan yang memiliki kecenderungan lifetime value dari konsumen. Dimana pada prinsipnya orang tua sebagai konsumen sekolah yang menentukan pendidikan untuk anaknya membutuhkan kenyamanan yang salah satunya dari implementasi customer relationship management.
\end{abstract}

Kata Kunci: Customer Relationship Management, Customer lifetime Value, Tourism.

\begin{abstract}
Competition in the education industry is increasingly felt, so that management of customer relationships is enforced. The paradigm and way of thinking of the education industry are no longer dominated by how to get new students, but on how to retain old customers. Examining the phenomenon of problems in the education industry, research is carried out related to the relationship between customer relationship management and customer lifetime value. The research was conducted in the education industry, where the parents of students were the consumers studied in this study. So that a survey was carried out to 100 parents of Tourism School students, namely the NHI Tourism Academy in Bandung, Indonesia. The study was conducted through regression analysis and the data were obtained quantitatively through a questionnaire. The results of the study found that customer relationship management carried out by schools has a significant impact on increasing customer lifetime value. Parents will provide recommendations on educational investment to their families and colleagues if they feel satisfaction with the services provided by the school. This research is certainly useful for the education industry which tends to the lifetime value of consumers. Where in principle parents as school consumers who determine education for their children need comfort, one of which is the implementation of customer relationship management.
\end{abstract}

Keywords: Customer Relationship Management, Customer lifetime Value, Tourism.

Diterima: 10 Okt 2020, Direvisi: 4 Jan 2021, Dipublikasi: 15 Feb 2021 


\section{PENDAHULUAN}

Pada jaman persaingan perusahaan yang semakin ketat, dunia industri seolah-olah menjadi sebuah dunia yang sangat kecil dan sempit. Hal ini dirasakan juga oleh industri pada sektor jasa (Ariyanto, 2005). Persaingan menjadi tingkat multinasional dikarenakan begitu pesatnya kemajuan teknologi dan transportasi, jarak dan negara bukan lagi halangan dalam berkompetisi . Begitu banyaknya tenaga-tenaga ahli asing yang masuk kedalam bidang pendidikan nasional, namun berusaha membawa ritme-ritme budaya internasional atau setidaknya budaya negara asal mereka kedalam nasionalisme budaya nasional kita. Belum lagi dibukanya MEA (Masyarakat Ekonomi Asia), yang mempermudah masuknya orang-orang asing dan makin memperketat persaingan di Indonesia (Syukriah \& Hamdani, 2015).

Persaingan industri juga masuk kedalam bidang pendidikan. Pendidikan merupakan aspek penting dari proses pembangunan nasional yang ikut menentukan pertumbuhan ekonomi suatu negara serta investasi yang memiliki manfaat ekonomi dan sosial jangka panjang bagi individu, masyarakat luas maupun bagi negara. Berdasarkan Amandemen Undang-Undang Dasar Negara Republik Indonesia Tahun 1945 dalam Pasal 31 ayat (1), bahwa setiap warga negara berhak mendapatkan pendidikan untuk mengembangkan potensi yang dimiliki secara optimal. Untuk mencapai tujuan tersebut, negara wajib menyediakan layanan pendidikan bermutu sesuai dengan minat dan bakat yang dimilikinya tanpa memandang status sosial, ras, etnis, agama dan gender. Dengan demikian, pendidikan menjadi syarat mutlak yang harus dipenuhi karena ia merupakan faktor determinan bagi suatu bangsa untuk bisa memenangi kompetisi global (Suciani, 2013).

Apalagi saat ini paradigma dalam memandang pendidikan mulai bergeser, yang awalnya pendidikan dilihat dan dikaji dari aspek sosial, sekarang orang melihat pendidikan lebih pada sebuah corporate. Jika logika corporate ini dipakai dalam dunia pendidikan, maka lembaga pendidikan dapat dimaknai sebagai sebuah lembaga yang bergerak dibidang layanan jasa pendidikan yang dibeli oleh para konsumen. Akan tetapi lembaga pendidikan memiliki ciri yang jelas berbeda dengan perusahaan atau organisasi bisnis yang berorientasi pada keuntungan finansial (Jonathan Sarwono, 2011).

Konsep bisnis dan pemasaran sudah saatnya diterapkan dalam lembaga pendidikan sehingga memiliki Competitive Advantage. Sebuah lembaga pendidikan harus berusaha mencapai keunggulan memberikan layanan prima dengan superior customer service dan menghasilkan lulusan yang berkualitas. Karena kualitas layanan lembaga pendidikan berbanding lurus dengan kepercayaan peminat layanan jasa pendidikan. Semakin bagus layanan pendidikan yang diberikan, maka semakin banyak pula peminat yang akan memanfaatkan jasa yang diberikan (Mundir, 2016).

Dalam hal ini, lembaga pendidikan dipahami sebagai lembaga yang memberikan layanan jasa pendidikan kepada siswa, mahasiswa, ataupun masyarakat umum. Oleh karena itu, pihak sekolah harus mengembangkan strategi pemasarannya agar mutu lembaga pendidikannya semakin meningkat dan dapat menarik banyak siswa. Etika pemasaran dalam dunia pendidikan adalah menawarkan mutu layanan intelektual dan pembentukan watak secara menyeluruh (Atika, 2016).

Jika lembaga ingin memberikan citra yang baik dalam rangka menarik jumlah siswa, maka konsekuensi logisnya lembaga pendidikan harus mengembangkan berbagai upaya strategi pemasaran sehingga customer tertarik untuk menggunakan jasa lembaga tersebut. Sebagai bentuk pertanggungjawaban dari pemasaran itu, sekolah harus berupaya semaksimal mungkin untuk mengelola serta meningkatkan kualitas layanannya sehingga apa yang dipromosikan bisa dipertanggungjawabkan (Mundir, 2016). Karena pendekatan marketing menuntut mereka untuk menganalisis intra dan ekstrakulikuler, fasilitas pendidikan, dan suasana belajar mengajar sehingga kegiatan mereka selalu terpusat pada perbaikan mutu pelayanan.

Apabila produsen tidak mampu memasarkan hasil produksinya, dalam hal ini jasa pendidikan disebabkan mutunya tidak dapat memuaskan konsumen, maka produksi jasa yang ditawarkan tidak laku. Strategi tersebut diadopsi dari dunia bisnis, dimana istilah marketing terfokus pada sisi kepuasan konsumen dengan memakai dasar pemikiran yang logis jika konsumennya tidak puas, berarti marketingnya gagal. Dengan kata lain, jika lembaga pendidikan yang memproses jasa pendidikan tidak mampu memuaskan users educations sesuai dengan need pasar, maka lembaga pendidikan tersebut tidak akan berlaku untuk terus eksis (Mundir, 2016).

Akademi NHI adalah bagian dari mitra pemerintah untuk memajukan pendidikan di Indonesia. Secara ringkas, Akademi NHI adalah 
sebuah lembaga pendidikan yang menggunakan Kurikulum Nasional dan International Primary Curriculum (IPC), dengan metode belajar mengajar berdasarkan pendekatan dan implementasi Kecerdasan Majemuk (Multiple Intelligences/MI) anak secara langsung dan konkrit. Profil sekolah ini lain dari sekolah pada umumnya, namun keberadaannya semakin dirasakan sebagai sebuah sekolah yang mampu mengakomodasi semua keinginan kita tentang dunia pendidikan yang kita harapkan, pendidikan yang membebaskan dan menyenangkan. Namun, substansinya sama dengan sekolah-sekolah lain, yaitu ingin mencetak generasi bangsa yang berkualitas sebagaimana tertulis dalam undangundang pendidikan.

Semakin banyak jumlah sekolah semakin ketat persaingan antar lembaga pendidikan di Indonesia. Namun dibalik semua itu, Akademi NHI juga dituntut untuk bisa berkembang secara maksimal, tidak hanya jasa yang ditawarkan namun yang paling penting pelayanan yang diberikan sekolah kepada konsumen. Dapat dibayangkan, seberapa besar keuntungan yang hilang begitu saja jika sekolah tidak mempedulikan atau menjalin hubungan yang baik dengan orang tua murid. Customer Relationship Management merupakan suatu strategi manajemen yang membahas mengenai penanganan hubungan antara sekolah dengan orang tua murid, atau dengan kata lain Customer Relationship Management mengubah pandangan filosofis lembaga pendidikan yang dahulunya berorientasi pada jasa saja namun sekarang lembaga pendidikan juga harus memperhatikan konsumen (customer focused) (Kumalasari, 2013).

Customer Relationship Management memiliki peran penting dalam sebuah lembaga pendidikan. Pada level aplikasi, Customer Relationship Management memang diterapkan untuk aktivitas pemasaran, seperti segmentasi pasar, mendapatkan konsumen baru, mempertahankan kesetiaan konsumen, mengembangkan konsumen, manajemen penjualan, dan manajemen kesempatan. Namun pada tingkatan strategis, Customer Relationship Management dapat digunakan sebagai teknologi yang mendukung misi suatu lembaga pendidikan dalam upaya meningkatkan orientasi pada para konsumennya. Data tentang konsumen yang mendukung strategi Customer Relationship Management dapat juga digunakan untuk berbagai kepentingan dalam sekolah, tidak hanya untuk aktifitas pemasaran saja akan tetapi manajemen operasional dapat memanfaatkan data konsumen untuk mendesain layanan khusus bagi para konsumen.

Dengan adanya sistem Customer Relationship Management, maka diharapkan agar antar sekolah dapat mengetahui bagaimana langkah-langkah atau cara-cara melayani orang tua murid, agar orang tua murid merasa puas karena apabila orang tua murid merasa puas dengan pelayanan sekolah, maka secara otomatis orang tua murid tersebut akan kembali lagi menggunakan jasa pendidikan yang sekolah tawarkan, atau bahkan menjadi konsumen tetap. Oleh karena itu, Customer Relationship Management secara bertahap telah diterapkan untuk meningkatkan hubungan antara sekolah dan orang tua murid. Karena pihak yayasan berkeyakinan bahwa hubungan antara sekolah dan orang tua murid adalah hubungan yang langsung dan intim, efek positif dari Customer Relationship Management secara signifikan akan meningkatkan Customer Lifetime Value. Tujuan utama Customer Relationship Management sebenarnya adalah untuk menemukan lifetime value dari konsumen. Setelah lifetime value didapat, tujuan selanjutnya adalah bagaimana agar lifetime value konsumen dapat terus diperbesar dari tahun ketahun (Mundir, 2016).

Customer Lifetime Value adalah cara untuk mengukur tingkat penerimaan konsumen dan cara mempertahankan konsumen dengan "benar" dalam konteks manajemen hubungan konsumen Customer Relationship Management. Menurut Berger dan Nasr (1998) Customer Lifetime Value sesungguhnya merupakan perbedaan antara biaya yang dikeluarkan untuk memperoleh, melayani, dan mempertahankan seorang pelanggan dengan pendapatan yang diperoleh dari konsumen dalam suatu customer lifecycle oleh karena itu, perlu untuk mengidentifikasi dan mengukur suatu nilai pelanggan (Aviliani, 2012). Customer lifecycle adalah penggambaran tahapan perjalanan seseorang sejak dia mempertimbangkan menjadi konsumen, menggunakan produk atau jasa hingga menjadi loyal terhadap produk atau jasa yang dibelinya (Hidayat, Muhammad, \& Suryotrisongko, 2012). Hal ini lahir dari persaingan antar lembaga pendidikan yang semakin ketat sehingga setiap sekolah mencoba menghasilkan suatu nilai lebih (Value Added) dari persaingan mereka yang nantinya nilai lebih tersebut menimbulkan citra yang baik dimata orang tua murid. Terlebih dengan semakin 
menjamurnya lembaga pendidikan yang memiliki sistem pendidikan yang serupa dengan Akademi NHI, jika tidak diimbangi dengan pengembangan kualitas yang semakin baik, juga pelayanan yang memuskan, maka lambat laun akan tertinggal dengan lembaga baru yang menawarkan berbagai kelebihan.

Perkembangan dunia teknologi dan informasi sekarang ini sangat pesat dikalangan masyarakat yang kemudian mengubah cara pandang mereka terhadap media penyedia informasi. Salah satu penerapan Customer Relationship Management yang termasuk dalam kategori operasional Customer Relationship Management adalah dalam bentuk aplikasi web. Website merupakan salah satu sarana media internet yang berfungsi untuk menampilkan, memperkenalkan bahkan dapat berfungsi sebagai median pelayanan dan pencari informasi yang sedang dibutuhkan oleh konsumen (Dyantina, Afrina, \& Ibrahim, 2012). Lembaga sekolah terutama yang masih sangat membutuhkan interaksi maupun sosialisasi agar dapat lebih dikenal masyarakat luas maupun siswa-siswanya sendiri, yaitu dengan cara memberikan informasi secara lengkap, detail dan jelas mengenai Akademi NHI. Namun, masih terdapat beberapa kekurangan yang terjadi dalam pelayanan website Akademi NHI. Hal ini di terbukti dengan masih kurang updatenya informasi mengenai sekolah, tidak ada fasilitas untuk pendaftaran online.

Akademi NHI dalam kegiatan penyampaian informasi masih perlu berinteraksi dan bersosialisasi agar lebih dikenal oleh masyarakat luas yaitu dengan cara memberikan informasi secara lengkap, detail dan jelas mengenai profil sekolah. Penyampaian informasi yang selama ini digunakan di Akademi NHI juga masih menggunakan cara konvensional. Cara konvensional tersebut antara lain penyampaian informasi dengan pemasangan spanduk dan melalui papan pengumuman ataupun brosur. Dengan penyebaran informasi yang demikian dirasakan masih memiliki banyak kekurangan, antara lain jangkauan penyebaran informasinya yang masih kurang luas, muatan informasi yang terbatas, proses update informasi yang kurang menguntungkan baik menyangkut biaya maupun waktu.

Namun satu hal yang harus disadari bahwa fasilitas dan data informasi konsumen yang ada hanya merupakan seperangkat alat bantu untuk mencapai tujuan akhir. Yang lebih diperhatikan adalah bagaimana komitmen sekolah itu sendiri untuk menjalin hubungan dengan orang tua murid serta aplikasi yang diterapkan sehingga nantinya hubungan antar sekolah dan orang tua murid untuk jangka waktu yang panjang tersebut dapat tercapai.

Selain itu, database konsumen yang kuat merupakan kunci utama pelaksanaan Customer Relationship Management. Database konsumen dapat dijadikan ukuran tentang nilai lembaga pendidikan sekarang dan kemungkinan performanya di masa mendatang (Hamidin, 2008). Untuk lembaga pendidikan mungkin akan lebih mudah karena jumlah konsumennya terbatas. Mengumpulkan database konsumen para orang tua murid di Akademi NHI pelaksanaannya juga masih menggunakan cara manual yaitu dengan mengisi data konsumen.

untuk pendaftaran calon murid baru dan data profil siswa/siswi di Akademi NHI masih mengisi data pribadinya secara manual belum menggunakan sistem teknologi atau sistem online sehingga database sekolah terkadang masih tidak tertata dengan rapih. Dengan profil yang lebih jelas, sekolah akan lebih mudah untuk melihat kebutuhan yang berbeda-beda dari setiap konsumen. Informasi ini tentu saja akan memudahkan sekolah untuk memberikan penawaran dan layanan yang sekolah tawarkan. Dengan tingkat kebutuhan yang dipetakan, sekolah juga dapat memberikan komunikasi pemasaran terpadu yang lebih personal dan customized. Konsumen akan merasa lebih diperlukan secara individual dan tentu saja akan memberikan pengalaman yang lebih menarik dan mendukung proses kepuasan konsumen. Dan tentu saja untuk jangka panjang adalah bagaimana hal tersebut dapat menciptakan Customer Lifetime Value untuk terus memakai pelayanan di Akademi NHI. Paradigma dan cara berpikir lembaga pendidikan tidak lagi didominasi pada bagaimana mendapatkan pelanggan baru, tetapi lebih ke bagaimana mempertahankan pelanggan lama. Karena menurut survey, biaya untuk mempertahankan pelanggan lama jauh lebih murah dari biaya untuk mendapatkan pelanggan baru.

Berdasarkan fenomena masalah yang telah terjadi di Akademi NHI Bandung, yang berkaitan dengan Customer Relationship Management dan Customer Lifetime Value, maka penelitian ini fokus mengkaji pengaruh Customer Relationship Management terhadap Customer Lifetime Value pada Akademi NHI Bandung. 
KAJIAN PUSTAKA

\section{Customer Relationship Management}

Customer Relationship Management merupakan suatu strategi yang menitik beratkan pada semua hal terkait pada konsumen. Menurut Wijaya \& Darudianto (2009), Customer Relationship Management adalah strategi yang digunakan dalam mempelajari kebutuhan dan perilaku pelanggan untuk membangun relasi yang kuat dengan pelanggan. Customer Relationship Management merupakan sebuah pendekatan untuk mengerti dan mempengaruhi tingkah laku pelanggan, yang dapat dilakukan melalui kemampuan berkomunikasi dalam meningkatkan pelayanan terhadap permintaan order pelanggan. Program Customer Relationship Management merupakan suatu proses interaksi pelanggan dengan sistem, dimana pelanggan dapat memperoleh informasi berguna seperti: status order, kontak person in charge, yang akhirnya bertujuan untuk dapat meningkatkan hubungan baik dengan pelanggan. Secara umum, solusi Customer Relationship Management adalah penyediaan informasi yang dibutuhkan untuk mendukung program penjualan, pelayanan dan pemasaran.

Menurut Hamidin (2008) Customer Realtionship Management merupakan sebuah filosofi bisnis yang menggambarkan suatu strategi penempatan client sebagai pusat proses, aktivitas dan budaya. Konsep ini telah dikenal dan banyak diterapkan untuk meningkatkan pelayanan di perusahaan. Customer Realtionship Management adalah usaha sebuah lembaga pendidikan untuk berkonsentrasi menjaga konsumen (agar tidak lari ke pesaing) dengan mengumpulkan segala bentuk interaksi konsumen baik itu lewat telepon, email, masukan di situs atau hasil pembicaraan dengan staff sales dan marketing atau dapat dikatakan sebuah strategi meyeluruh dari suatu lembaga pendidikan yang memungkinkan lembaga pendidikan tersebut untuk mengelola hubungan baik dengan konsumen atau orang tua murid.

Menurut Yahya (2008:82) Customer Realtionship Management adalah sebuah strategi bisnis menyeluruh dalam suatu perusahaan yang memungkinkan perusahaan tersebut secara efektif bisa mengelola hubungan dengan para pelanggan. Dengan demikian melalui Customer Realtionship Management lembaga pendidikan dapat melakukan pendekatan sehingga dapat menarik sejumlah informasi mengenai kebutuhan dan keinginan konsumen.
Berdasarkan beberapa pengertian diatas dapat disimpulkan bahwa Customer Realtionship Management adalah suatu konsep manajemen secara menyeluruh yang berpusat pada konsumen atau orang tua murid sebagai faktor utama untuk meningkatkan keunggulan bersaing dan bertujuan memperoleh tingkat kepuasan pelanggan secara maksimum yang akan membawa keuntungan bagi lembaga pendidikan dengan biaya yang relatif lebih rendah dan mendapat kesetiaan dari para konsumennya.

\section{Customer Lifetime Value}

Pengelolaan nilai konsumen menegaskan komitmen lembaga pendidikan menjadikan konsumen sebagai aset yang secara langsung memberikan dampak pertumbuhan pasar serta finansial secara berkelanjutan. Penciptaan, penambahan serta pemeliharaan nilai konsumen dari masa ke masa (lifetime) menjadi faktor kunci keberhasilan bagi lembaga pendidikan untuk mempertahankan keunggulan bersaingnya terhadap para pesaing antar sekolah lainnya (Jusran Buraera, Abd. Rahman Kadir, 2014). Dalam pemasaran perlu mempertahankan konsumen, disamping menciptakan konsumen yang baru, karena biaya untuk mempertahankan konsumen lebih murah dari pada biaya untuk mencipkan konsumen yang baru. Salah satu tugas dari pemasaran adalah menciptakan, menyediakan, dan menangkap nilai dari para konsumennya. Pengertian dari nilai pelanggan itu sendiri menurut Butz \& Goodstein yang dikutip oleh Tjiptono (2011:374) menyatakan bahwa nilai pelanggan adalah ikatan emosional yang terjalin antara konsumen dan pihak sekolah setelah konsumen menggunakan jasa yang dihasilkan tersebut dan mendapati bahwa jasa yang bersangkutan memberikan nilai tambah. Sedangkan menurut Soegoto (2009:56) mengemukakan bahwa Customer Value merupakan emotional bond yang ada antara produsen dan konsumen setelah konsumen menggunakan jasa yang dihasilkan dan memperoleh nilai tambah atas jasa tersebut. Dalam mempertahankan konsumen lama dengan membangun hubungan yang kekal dengan harapan untuk menjadikan pelanggan seumur hidup yang sering disebut Customer Lifetime Value .

Definisi customer lifetime value lainnya dikutip dari beberapa ahli oleh Sitomorang (2010) seperti terdapat dibawah ini. 
1. Penjumlahan keuntungan yang dihasilkan oleh seorang pelanggan dari serial waktu pada periode waktu diskrit [Mulhern 1999: 25-40].

2. Nilai hubungan pelanggan yang dinyatakan dalam monetary term [Bell et al 2002: 80-1].

3. Discounted value dari masing-masing pelanggan pada expected lifetime sebagai pelanggan suatu perusahaan [Lovelock and Wirtz 2004: 354-5].

4. Penjumlahan dua net present value, yaitu return on acquisition spending dua return on retention spending [Ching et al 2004: 860-67].

5. Keuntungan yang diperolah perusahaan karena memiliki hubungan pelanggan pada jangka waktu tertentu [Mengadaptasi Lovelock and Writz 2004: 354-5].

Perubahan paradigma pemasaran yang baru menyebabkan terjadinya transformasi dari brandcentric manuju customer-centric dan sebagai konsekuensinya maka identifikasi konsumen menjadi penting.

Customer Lifetime Value telah diteliti oleh Ryals dan Knox (2003); Liu et al (2007); Anna dan Ribeiro (2009); dan Tsai et al (2013), dengan hasil penelitian yang menjelaskan bahwa Customer Lifetime Value menjadi hal penting bagi lembaga pendidikan dalam rangka menjalin hubungan yang berkesinambungan antara pihak sekolah dengan konsumen. Menurut Tukel dan Dixit (2013) bahwa dalam manajemen hubungan pelanggan, penentuan Customer Lifetime Value penting untuk memahami dan mengevaluasi hubungan sekolah dengan konsumen. Menurut Osterwalder dan Pigneur (2009), sebuah lembaga pendidikan idealnya akan menjelaskan dasar pemikiran tentang bagaimana lembaga pendidikan mampu menciptakan (create), menyampaikan (deliver), dan menangkap (capture) nilai-nilai (value) yang dapat dijelaskan melalui 9 (sembilan) elemen generic atau pilar utama atau disebut 9 building blocks of Business Model, yakni segmen konsumen (customer segment), nilai keunggulan produk (value preposition), saluran distribusi (delivery channel), hubungan konsumen (customers relationship), komponen pendapatan (revenue stream), sumberdaya utama(key resources), kegiatan utama(key activities), partner utama (key partnership) dan struktur biaya (cost structure) (Sundari, 2008).

Berdasarkan beberapa pengertian diatas dapat disimpulkan bahwa Customer Lifetime Value adalah gabungan antara konsep dengan pengukuran. Intinya, Customer Lifetime Value adalah mengoptimalkan antara interaksi dengan percakapan dalam rangka menciptakan ikatan hubungan konsumen yang akan mengantarkan pada retensi konsumen, pengulangan pembelian, rujukan atau rekomendasi konsumen, mengurangi biaya pendukung, dan bahkan mungkin harga premium. Penting untuk memahami bagaimana Customer Lifetime Value berpengaruh karena para konsumen bergerak melalui perjalanan dengan organisasi. Hubungan antara Customer Lifetime Value dengan perjalanan konsumen meliputi akuisisi, dukungan, retensi, loyalitas, dan advokasi. Kelima hal tersebut saling berkaitan dalam sebuah siklus. Adapun secara konseptual keterkaitan antar variabel tersebut dapat dilihar pada Gambar 1.

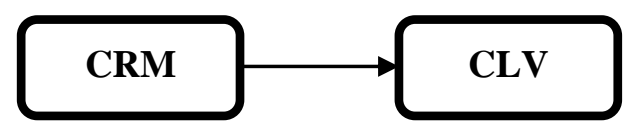

\section{Gambar 1 Kerangka Pemikiran}

Berdasarkan kerangka pemikiran tersebut, maka hipotesis dalam penelitian ini adalah sebagai berikut:

H1 : Customer Relationship Management berpengaruh terhadap Customer Lifetime Value di Akademi NHI Bandung.

\section{METODOLOGI PENELITIAN}

Lokasi penelitian yang dipilih peneliti untuk memperoleh data penelitian ini melalui penyebaran angket kepada responden yaitu orang tua di Akademi Pariwisata NHI Bandung. Jenis penelitian yang digunakan dalam penelitian ini adalah penelitian kuantitatif yang mencakup metode survey, sedangkan alasan menggunakan penelitian kuantitatif untuk meneliti sebuah populasi atau sampel tertentu, menguji hipotesis yang telah ditetapkan dan ingin mendapatkan data yang akurat.

Populasi dalam penelitian ini adalah seluruh orang tua murid di Akademi Pariwisata NHI Bandung. Metode yang digunakan dalam pengambilan sampel adalah nonprobability sampling dengan teknik Sampel yang digunakan penelitian ini adalah sampel jenuh karena penelitian ini mengambil seluruh populasi untuk dijadikan sumber data. Ada dua jenis data yang digunakan dalam penelitian ini, yaitu data primer diperoleh melalui studi lapangan dan penyebaran angket ke tempat yang sudah di tentukan peneliti dan data sekunder yang digunakan dalam penelitian ini berasal dari jurnal, artikel, majalah 
marketing, dan dari buku-buku marketing. Angket dalam penelitian ini telah lolos uji validitas. Selain itu angket yang digunakan juga telah lolos uji reliabilitas dengan nilai cronbbach's alpha masing - masing variabel > 0,60 Sujarweni (2015).

\section{HASIL DAN PEMBAHASAN}

\section{Analisis Deskriptif}

Gambaran mengenai Customer Relationship Management dan Customer Lifetime Value di Akademi Pariwisata NHI Bandung dapat diketahui melalui perhitungan rekapitulasi tanggapan responden. Berdasarkan hasil penelitian pada responden melalui penyebaran kuesioner terhadap 80 responden dan perhitungan rekapitulasi tanggapan responden menyatakan bahwa Customer Relationship Management dan Customer Lifetime Value di Akademi Pariwisata NHI Bandung dapat dikatakan "baik".

\section{Analisis Regresi Linear Sederhana}

Model persamaan regresi linear sederhana Customer Relationship Management dan Customer Lifetime Value di Akademi Pariwisata NHI Bandung dapat diketahui melalui perhitungan rekapitulasi tanggapan responden. Berdasarkan hasil penelitian pada responden melalui penyebaran kuesioner terhadap 80 responden dan perhitungan rekapitulasi tanggapan responden menyatakan bahwa Customer Relationship Management dan Customer Lifetime Value di Akademi NHI Bandung dapat

yang akan dibentuk pada penelitian ini sebagai berikut:

$$
\begin{aligned}
& \mathrm{Y}=\mathrm{a}+\mathrm{bX} \\
& \mathrm{Y}=6.272 .+0,414 \mathrm{X}
\end{aligned}
$$

Dimana :

$\mathrm{Y}=$ Subyek dalam variabel dependen yang diprediksikan

$\mathrm{a}=$ Harga $\mathrm{Y}$ ketika harga $\mathrm{X}=0$ (harga konstan)

$\mathrm{b}=$ Angka arah satu koefisien regresi, yang menunjukan angka pengingkatan ataupun penurunan variabel dependen yang didasarkan para perubahan variabel independen. Bila (+) arah garis naik, dan bila (-) maka arah garis turun.

$\mathrm{X}=$ Subyek pada variabel independen yang mempunyai nilai tertentu.

Karena nilai koefisien regresi bernilai plus (+), maka dengan demikian dapat dikatakan bahwa Customer Relationship Management berpengaruh positif terhadap Customer Lifetime Value.

\section{Pengaruh Customer Relationship Management Terhadap Customer Lifetime Value}

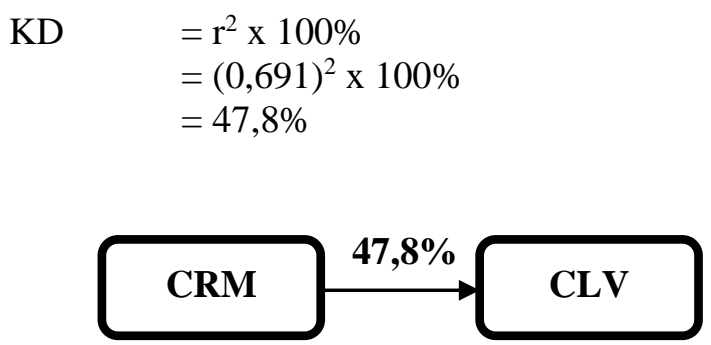

\section{Gambar 2 Customer Relationship Management Terhadap Customer Lifetime Value}

Nilai pada koefisien determinasi tersebut dapat diketahui dari output koefisien korelasi pada lambang R. Hasil perhitungan tersebut menunjukan bahwa Customer Relationship Management berpengaruh sebesar 47,8\% terhadap Customer Lifetime Value.

\section{Pengujian Hipotesis}

Berdasarkan hasil perhitungan pada coefficients tabel $\mathrm{t}$ didapat bahwa $\mathrm{t}$ hitung adalah 8,452 , dan pada $t$ tabel adalah 1,990, maka dapat diambil kesimpulan dengan $\mathrm{t}$ hitung $>\mathrm{t}$ tabel.

$\mathrm{H}_{\mathrm{o}}$ : tidak ada pengaruh Customer Relationship Management terhadap Customer Lifetime Value, secara signifikan ditolak

$\mathrm{H}_{\mathrm{a}}$ : ada pengaruh Customer Relationship Management terhadap Customer Lifetime Value, artinya diterima secara signifikan.

\section{KESIMPULAN DAN REKOMENDASI}

Berdasarkan hasil penelitian menunjukkan bahwa gambaran mengenai Customer Relationship Management dan Customer Lifetime Value di Akademi Pariwisata NHI Bandung sudah dapat dikatakan "Baik" dan berdasarkan penelitian, Customer Relationship Management berpengaruh positif dan signifikan terhadap ustomer Lifetime Value pada orang tua murid Akademi Pariwisata NHI Bandung sebesar 47,8\%. Penelitian ini menunjukan bahwa Customer Relationship Management yang baik pada industri pendidikan mampu meningkatkan citra institusi pendidikan terutama pada Customer Lifetime Value. Customer Lifetime Value tentunya berkaitan dengan rekomendasi orang tua yang 
tetap berfikir positif kepada institusi pendidikan dan kembali mempercayaan anaknya untuk memilih institusi tersebut. Penelitian ini memiliki batasan dimana kajian fokus pada Customer Lifetime Value, dan tidak mengkaji dampaknya pada industri pariwisata. Sehingga menjadi saran pada penelitian lanjutan untuk mengkaji hal tersebut.

\section{DAFTAR PUSTAKA}

Ariyanto, T. (2005). Profil Persaingan Usaha dalam Industri Perbankan Indonesia. Komisi Pengawas Persaingan Usaha (KPPU). Perbanas Finance \& Banking Journal, 6(2), 95-181.

Atika, I. M. (2016). Segmentasi dan Positioning Jasa Pendidikan. Jurnal Manajemen Pendidikan Islam, 1(November), 153-168.

Aviliani. (2012). Membangun loyalitas nasabah simpedes dengan metode customer lifetime value. Finance and Banking, 14(1), 73-88.

Dyantina, O., Afrina, M., \& Ibrahim, A. (2012). Penerapan Customer Relationship Management (CRM) Berbasis Web (Studi Kasus Pada Sistem Informasi Pemasaran di Toko YEN-YEN) 1,2,3. Sistem Informasi, 4(2), 516-529. Retrieved from http://ejournal.unsri.ac.id/index.php/jsi/inde $\mathrm{x}$

Hamidin, D. (2008). Model Customer Relationship Management ( Crm ). Seminar Nasional Aplikasi Teknologi Informasi 2008 (SNATI 2008), 2008(Snati), 31-34.

Hidayat, A. N., Muhammad, N. A., \& Suryotrisongko, H. (2012). Integrasi Aplikasi Android dan Komputer Server sebagai Solusi Mobile Commerce dan CRM Studi Kasus Toko Game XYZ. Seminar Nasional Teknologi Informasi \& Komunikasi Terapan 2012 (Semantik 2012) Semarang, 23 Juni 2012 ISBN, 2012(Semantik), 108-113.

Jonathan Sarwono. (2011). Faktor-Faktor Pendorong Persaingan Bisnis: Aplikasi Penawaran Jasa Pendidikan. Jurnal Pendidikan Penabur, 16(Jun), 94-109. https://doi.org/10.1017/CBO978110741532 4.004
Jusran Buraera, Abd. Rahman Kadir, S. A. (2014). No Title. Analisis, 3(2), 165-171.

Kumalasari, V. (2013). Analisis Penerapan Customer Relationship Management Studi Kasus Pada Gkmi Anugerah Rayon Kembangan. Ilmiah Manajemen Bisnis, 13(1), 11-22.

Mundir, A. (2016). STRATEGI PEMASARAN JASA PENDIDIKAN MADRASAH. Strategi Pemasaran Jasa Pendidikan Madrasah, 7, 27-40.

Suciani, A. A. R. S. N. K. (2013). FENOMENA POKOK PENDIDIKAN INDONESIA: APA DAN BAGAIMANA? SOSHUM JURNAL SOSIAL DAN HUMANIORA, 3(1), 96-107.

Sundari, S. (2008). Customer Delight. Fokus Ekonomi, $\quad 7(1), \quad$ 44-51. https://doi.org/10.1177/1094670511425698

Syukriah, A., \& Hamdani, I. (2015). PENINGKATAN EKSISTENSI UMKM MELALUI ADVANTAGE DALAM RANGKA MENGHADAPI MEA 2015 DI TEMANGGUNG. Economics Development Analysis Journal, 2(2), 110-119. 